\title{
Septopreoptic holoprosencephaly
}

INSERM

\section{Source}

INSERM. (1999). Orphanet: an online rare disease and orphan drug data base.

Septopreoptic holoprosencephaly. ORPHA:280195

Septopreoptic holoprosencephaly (HPE) is a very rare subtype of lobar HPE (see this term) characterized by midline fusion limited to the septal and/or preoptic regions of the telencephalon without a significant frontal neocortical fusion. 